Antoniades K, Ishizaka A. Experimental evaluation of the appropriateness of an interactive inconsistency correction, International Symposium of the Analytic Hierarchy Process 2014, Washington D.C., U.S.A.

\title{
EXPERIMENTAL EVALUATION OF THE EFFECTIVENESS OF AN INTERACTIVE INCONSISTENCY CORRECTION
}

\author{
Kyriacos Antoniades, Alessio Ishizaka \\ Portsmouth Business School \\ University of Portsmouth \\ Richmond Building, Portland Street, \\ Portsmouth, PO1 3DE \\ E-mail: kyriacos.antoniades@port.ac.uk, alessio.ishizaka@port.ac.uk
}

\begin{abstract}
In a previous experimental study, it was observed that an automatic correction of inconsistency worsens the preference representation of the decision maker. In this paper, a new experimental study investigates if decision makers' preferences are better represented using an interactive inconsistency correction technique. The experimental results show that an interactive approach does indeed-not better represent decision makers' preferences for both both-the suebjective and subjective measures; although in the latter case it is not pereeived as strchand objective measures. Therefore, the interactive effort to reduce inconsistencies is not justified.
\end{abstract}

Keywords: AHP, Consistency, Goal Programming, Interactive, Preferences.

\section{Introduction}

The Analytic Hierarchy Process (AHP) is one of the most popular multi-criteria decision making (MCDM) method. Its success is widely accepted as it has been extensively implemented exty in many organizations to support their decisions. One of tits main advantage stems from utilizing information redundancy to check for inconsistency. However, if inconsistency is too high, some of the pairwise comparisons may need to be reconsidered, before calculating priorities. Several techniques have been developed for this task. In this paper, the automatic correction of inconsistency is compared with an interactive correction. It is observed that neither the automatic nor the interactive approach do not better represents better the decision makers' preferences, at least for both the subjective and objective measurable alternatives; which is not the case for the autematic approach.

\section{Hypotheses/Objectives}

Linares (2009) found, in an experimental study, that automatic inconsistency correction with goal programming (Gonzalez-Pachon \& Romero, 2004) worsen the ranking representation of decision makers. Successively, Linares (2009) states: "It would be interesting to replicate this experiment when the improvements in consistency are achieved through an interaction with the decision maker, as Saaty (1980) proposed originally." This paper attempts to answer the following research questions:

1. Does the interactive approach improve consistency?

2. Does the interactive approach better represents participants' preference of rankings?

International Symposium of

1

Washington, D. C. the Analytic Hierarchy June 29 - July 2, 2014

Process 
Antoniades K, Ishizaka A. Experimental evaluation of the appropriateness of an interactive inconsistency correction, International Symposium of the Analytic Hierarchy Process 2014, Washington D.C., U.S.A.

3. For the objective measures which preference of rankings is closest to the real measure?

\section{Research Design/Methodology}

Two separate experiments are conducted in the following order (always start with the subjective alternatives):

a) Decision with subjective alternatives: Participants are asked to compare pairwise their preferred mode of transportation (Train, Coach, Taxi, Car sharing and Own car), to travel from Portsmouth to Gatwick airport to take a flight for a short week-end break.

b) Decision with objective measurable alternatives: Participants are asked to evaluate the closest distance of five cities (Cardiff, London, Edinburgh, Southampton, and Liverpool) to Portsmouth.

During the experiment, three rankings are produced by the participants:

1. Original Ranking $\left(\mathrm{R}_{\mathbf{0}}\right)$, where the priorities are calculated by the eigenvector method without any inconsistency correction.

2. Automatic Ranking $\left(\mathrm{R}_{\mathrm{A}}\right)$, where inconsistencies are corrected automatically using the goal programming method.

3. Interactive Ranking $\left(\mathrm{R}_{\mathrm{I}}\right)$, where the decision analyst collaborates with the participant to detect and correct the most inconsistent pairwise comparisons to the least one.

The procedure is exactly the same for both experiments:

1. The decision problem is explained to participants.

2. The participant compares pairwise the five alternatives.

3. The Consistency Ratio (CR), the Original Ranking $\left(\mathrm{R}_{\mathrm{O}}\right)$ and the Automatic Ranking $\left(\mathrm{R}_{\mathbf{A}}\right)$ are calculated.

4. If the consistency ratio is acceptable, i.e. below $10 \%$, the experiment terminates.

5. If the matrix is inconsistent, the inconsistency of each pairwise comparison, $I_{i j}$ is calculated with:

$$
I_{i j}=a_{i j}-\frac{p_{i}}{p_{j}}
$$

where, $a_{i j}$ is the pairwise comparison of alternative $i$ with $j$ and $p_{i}, p_{j}$ are their respective priorities (Saaty, 2003).

6. The participant is asked if (s)he wants to revise the most inconsistent comparison. If (s)he does not want to revise, then (s)he is asked if (s)he wants to revise the next most inconsistent comparison. If (s)he revises the comparison, the process restarts from point 4 until the inconsistency falls below $10 \%$ or the participant does not want to revise any of their entries.

7. The final Interactive Ranking $\left(\mathrm{R}_{\mathrm{I}}\right)$ is calculated.

8. The participant is asked which of the three ranking (without knowing how they have been calculated) represent the best his/her preferences. At the end of the experiment, a questionnaire is completed with participant's demography details as well as feedbacks on the research study. 
Antoniades K, Ishizaka A. Experimental evaluation of the appropriateness of an interactive inconsistency correction, International Symposium of the Analytic Hierarchy Process 2014, Washington D.C., U.S.A.

The program has been developed in Excel; based on a modified Excel template by Goepel (2013) with an embedded link to LINGO to calculate the Automatic Ranking $\left(\mathbf{R}_{\mathbf{A}}\right)$ using the goal programming method.

\section{Data/Model Analysis}

A number of observations are made on 31 participants, these include:

| C: Number of detections and corrections (Changes $\quad$ Revisions) of the inconsistent pairwise comparisons.

$\mathrm{N}$ : Number of declined revisions. When participants do not wish to change their pairwise comparison; the next most inconsistent element is considered

$\mathrm{CR}_{\mathrm{i}}$ : Initial Consistency Ratio (CR) at the first completion of the matrix.

$\mathrm{CR}_{\mathrm{f}}$ : $\quad$ Final Consistency Ratio (CR), i.e. when it reaches an inconsistency below $10 \%$ or when the participant does not want to revise any of his/her entries.

$\Delta \mathrm{CR}: \quad$ Difference between initial and final Consistency Ratio (i.e. $\Delta \mathrm{CR}=\mathrm{CRi}-\mathrm{CR}_{\mathrm{f}}$ ).

PR: $\quad$ Participant's Choice of ranking (i.e. Original, Automatic or Interactive).

$\mathrm{RR}_{\mathrm{A}}$ : $\quad$ Rank Reversal in the Automatic Ranking with respect to the Original Ranking.

$\mathrm{RR}_{\mathrm{I}}$ : $\quad$ Rank Reversal in the Interactive Ranking with respect to the Original Ranking.

Close: Participant's Choice of $r$ Ranking which is close to the real measure.

Table 1. Participant's choice of rankings for subjective and objective measures. 
Antoniades $K$, Ishizaka A. Experimental evaluation of the appropriateness of an interactive inconsistency correction, International Symposium of the Analytic Hierarchy Process 2014, Washington D.C., U.S.A. 
Antoniades K, Ishizaka A. Experimental evaluation of the appropriateness of an interactive inconsistency correction, International Symposium of the Analytic Hierarchy Process 2014, Washington D.C., U.S.A.

The results obtained are shown in Table 1. The shaded rows in Table 1 show experiments, where no revisions $(\mathrm{C}=0)$ are made.

Nine participants of the subjective problem and thirteen participants of the objective problem are excluded for the first and second research question because no consistency correction method was used. ; implying a preference for the OThe results obtained are shown in. Statistieal analysis reveals the following results The following hypotheses are tested:

\section{| Hypothesis 1: Does $t$ The interactive method improves consistency.?}

For the decisions-problem with subjective alternatives,_-it appears that improvements in consistency $(n=22)$ are disproportionately over-represented and compared to no improvements in consistency $(n=\underline{0} 9)$ are under-represented. The-eststatistical results, $\boldsymbol{\chi}^{z}$ $(1, \mathrm{n}-31)=22.005 .45, p$-(significanee-threshold) $p<.05$, confrms that the interactiv methods significantly improve consistency.

indieate that the frequencies of consistency improvements by the interactive method are not equally distributed; frequencies are statistically different from what would be expected by chance.

For the problem with the-objective measures, it appears that the improvements in consistency $(\mathrm{n}=18)$ are disproportionately over-represented with compared to no 
Antoniades K, Ishizaka A. Experimental evaluation of the appropriateness of an interactive inconsistency correction, International Symposium of the Analytic Hierarchy Process 2014, Washington D.C., U.S.A.

improvements in in-consistency $(\mathrm{n}=\underline{0} 13)$.- The Chi-square teststatistical results, $\chi^{2}(1, \mathrm{n}$

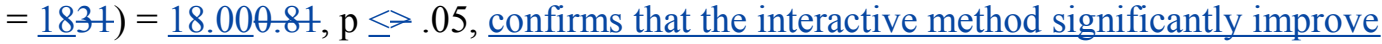
consistency.that there is no significant improvement in consistenction the frequencies of improvements by the interactive method are equally distributed, frequeneies are statistieally similar from what would be expeeted by ehanee.

\section{Hypothesis 2: Does $t \underline{T h e}$ interactive method better represent participants' preference of ranking.?}

The shaded rows in Table 1 show experiments, where there are no consistency improvements $(\triangle C R=0)$ or where the final eonsisteney is not below the threshold $\left(\mathrm{CR}_{\mathrm{f}} \rightarrow\right.$ $\theta .1$. These results are exeluded for the seeond researeh question beeatuse when $\triangle C R=0$, it shows that participants either were consistent in their initial attempt $\left(\mathrm{CR}_{i}<0.1\right)$ or deelined to revise any of their pairwise eomparisons ( $\left(\mathrm{CR}_{\mathrm{i}}=\mathrm{CR}_{\mathrm{f}}\right)$; implying a preferenee for the Original Ranking ( $\left.R_{\theta}\right)$. Moreover, as we are interested in comparing participants' preference of rankings with respect to $C R_{f}<0.1$, any experiments above the threshold are also excluded.

For the problem with subjective measures, it appears that the interactive method $(n=9)$ is proportionately represented with the automatic method $(\mathrm{n}=7)$ and the original method (n =6). The Chi-square test, $\chi^{2}(2, n=22)=0.64, p>.05$, does not confirm the hypothesis.

For the decisions-problem with objective measurable alternatives, it appears that the interactive method-ranking is $(\mathrm{n}=1 \underline{3} z)$ is disproportionately over-represented and the with the original method-ranking $(n=\underline{5} 4)$ is under-represented. TThe statistical

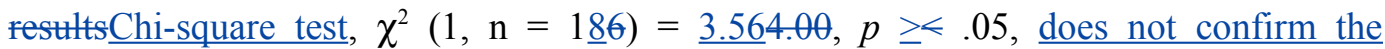
hypothesisindieate that the frequeneies of preferenee of rankings by the interaetive method are not equally distributed within this elass; frequeneies are statistieally different from what would be expected by chance.

For the decisions-with subjective measures it appears that the interactive method $(n-8)$ is proportionately represented with the automatic method $(n-5)$ and the original method $(n-4)$. The statistical results $-\chi^{2}(2, n-17)-1.53, p>.05$, pothesis.

indieate that the frequeneies of improvements by the interaetive method are equally distributed; no statistieal conelusions ean be dedueed for deeisions with subjective alternatives, whether the interaetive, automatic or the original method better represents participants' preference of rankings.

Hypothesis 3: The original ranking is closest to the real values For the objective measures which preference of rankings is closest to the real measure?

For the decisions-problem with objective measurable alternatives, it appears that the preference rankings that are closest to the real measures tsing is the original ranking approach $(\mathrm{n}=20)$. It is are-disproportionately over-represented compared with, with the interactive ranking approach $(\mathrm{n}=9)$ and the automatic ranking approach $(\mathrm{n}=2)$-are under-represented. The statistical results, $\chi^{2}(2, \mathrm{n}=31)=15.94, p<.05$ confirms that the original value is the closest to the real value, indicate that when the frequencies of the partieipants' preferenee of ranking is elosest to the real measure using an original ranking 
Antoniades K, Ishizaka A. Experimental evaluation of the appropriateness of an interactive inconsistency correction, International Symposium of the Analytic Hierarchy Process 2014, Washington D.C., U.S.A.

approach, are not equally distributed; frequeneies are statistically different from what would be expected by chance.

\section{Limitations}

In this experimental study, only two decision problems were used. Other problems need to be analyzed to confirm our observations.

\section{Conclusions}

The statistical results show that the interactive method does improves consistency for both the subjective and objective measures, $\bar{g}$ which is not determined for the objective measures. Nevertheless, the objective measures better represent participants' preference of rankings, which cannot be concluded for the subjective measures. In other words, it ean be dedueed that despite that the interative method better represents patieipants' preference of rankings for the objective measures, it is even m However, it is observed that the interactive approach does not better represent the decision makers' preferences, for both the subjective and objective measurable alternatives. ore likely to better represent their preference of rankings for subjective measures; but it is not pereeived as streh.

In additionMoreover, the results also show, that participants' preference of ranking which is closest to the real measure eomes from usingis given by the original ranking approach, which indicate that the effort to reduce inconsistencies using the interactive approach is bet justifiedto-

Nevertheless, this is a general statement, as if more participants' data were available, then a better understanding of the relationship between consistency improvement and rank reversal with respect to obtaining results close to the real measure could have been obtained.

The above conelusions eventtually lead us to seek further investigation to observe how the results of this experiment would vary, if we reversed the order of eondueting our experiment; that is, to start the experiment with the objective measures first, then run the experiment with the subjective measures. In this way, the partieipant will gain a better understanding and familiarity of the AHP methodology using the objective measure initially; then the participant would perhaps better perceive their preference of rankings for the subjective measures.

\section{Key References}

Goepel, K. D. (2013). Implementing the analytic hierarchy process as a standard method for multi-criteria decision making in corporate enterprises-A mew AHP excel template with multiple inputs. IMPLEMENTING THE ANALYTIC HERARCHY PROCESS AS A STANDARD METHOD FOR MULTI-CRITERIA DECISION MAKING IN CORPORATE ENTERPRISES-A NEW AHP EXCEL TEMPLATE WITH MULTIPLE INPUTS. Retrieved from http://bpmsg.com/new-ahp-exceltemplate-with-multiple-inputs/ 
Antoniades K, Ishizaka A. Experimental evaluation of the appropriateness of an interactive inconsistency correction, International Symposium of the Analytic Hierarchy Process 2014, Washington D.C., U.S.A.

Gonzalez-Pachon, J., \& Romero, C. (2004). A method for dealing with inconsistencies in pairwise comparisons. European Journal of Operational Research, 158(2), 351361. Retrieved from http://ideas.repec.org/a/eee/ejores/v158y2004i2p351-361.html

Linares, P. (2009). Are inconsistent decisions better? An experiment with pairwise comparisons. European Journal of Operational Research, 193(2), 492-498. doi:10.1016/j.ejor.2007.11.030

Saaty, T. L. (1980). Analytic Hierarchy Process (p. 287). McGraw Hill Higher Education. Retrieved from http://www.amazon.co.uk/Analytic-Hierarchy-ProcessThomas-Saaty/dp/0070543712

Saaty, T. L. (2003). Decision-making with the AHP: Why is the principal eigenvector necessary? European Journal of Operational Research, 145(1), 85-91. doi: $10.1016 / \mathrm{S} 0377-2217(02) 00227-8$ 